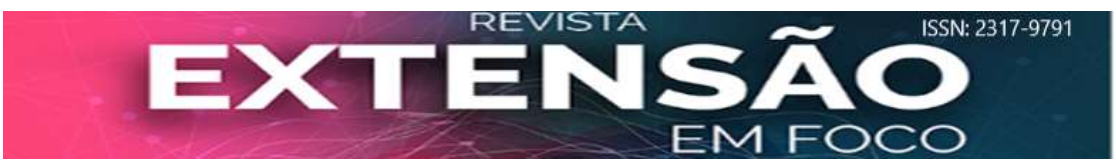

\title{
CONSTRUÇÃO DE UM PCE: O LIXO DE CASA RECICLADO NA ROBÓTICA
}

\author{
Aline Lucielle Sllva ${ }^{1}$ \\ Danieli Martins Leffer ${ }^{2}$ \\ Jonathan Faraco França ${ }^{3}$ \\ Levi Hulse ${ }^{4}$ \\ Madalena Pereira da Silva ${ }^{5}$ \\ Marlene Zwierewicz ${ }^{6}$ \\ Vanessa Tumelero ${ }^{7}$ \\ Recebido em: 10 out. 2020 \\ Aceito em: 11 nov. 2020
}

\begin{abstract}
RESUMO: A sociedade tem vivenciado inúmeros eventos naturais e/ou provocados pelo homem. Tais eventos nos fazem refletir e repensar sobre as atitudes e os modos de ser e viver. Diante da pandemia, veio o isolamento social e, neste contexto, a tecnologia tornou-se propicia para novas formas de ensinar e aprender em tempos de COVID-19. Visualizando esta possibilidade, este estudo tem por objetivo propor um Projeto Criativo Ecoformador (PCE) que permite trabalhar a robótica educacional de forma remota, na perspectiva transdisciplinar e que estimule a participação da família. A metodologia do estudo é de abordagem qualitativa e quanto aos objetivos, é de natureza exploratória, com procedimento bibliográfico. O PCE proposto consiste na construção de um robô com uso de material reciclável para re(significar) conceitos que já foram estudados e correlacioná-los a outros conteúdos, como matemática, ciências e artes.
\end{abstract}

Palavras-chave: Projeto Criativo Ecoformador. Robótica Educacional. Reciclagem.

\section{CONSTRUCTION OF A PCE: RECYCLED HOUSE WASTE IN ROBOTICS}

ABSTRACT: Society has experienced numerous natural or man-made events that make us reflect and rethink attitudes and ways of being and living. In the face of the pandemic, social isolation came and, in this context, technology became propitious for new ways of teaching and learning in times of COVID-19. Visualizing this possibility, this study aims to propose a creative eco-trainer project (PCE) that allows working on educational robotics in a remote, transdisciplinary way and encouraging family participation. The methodology of

\footnotetext{
${ }^{1}$ Mestranda em Educação Básica Universidade do Alto Vale do Rio do Peixe - UNIARP. ORCID: 00000002-9226-8818. E-mail: sb.aline@outlook.com.

${ }^{2}$ Mestranda em Educação Básica Universidade do Alto Vale do Rio do Peixe - UNIARP. ORCID: 00000002-9672-2715. E-mail: martinsdanieli548@gmail.com.

${ }^{3}$ Mestrando em Educação Básica Universidade do Alto Vale do Rio do Peixe - UNIARP. ORCID: 00000002-2493-1075. E-mail: jonathanfaracofranca@yahoo.com.br.

${ }^{4}$ Doutor do Programa de Pós-Graduação em Educação Básica da Universidade do Alto Vale do Rio do Peixe - UNIARP. ORCID: 0000-0002-1783-6707. E-mail: levihulse@uol.com.br.

${ }^{5}$ Doutora do Programa de Pós-Graduação em Educação Básica da Universidade do Alto Vale do Rio do Peixe - UNIARP. ORCID: 0000-0002-8886-2822. E-mail: madalena.pereira@uniarp.edu.br.

${ }^{6}$ Doutora do Programa de Pós-Graduação em Educação Básica da Universidade do Alto Vale do Rio do Peixe - UNIARP. ORCID: 0000-0002-5840-1136. E-mail: marlene@uniarp.edu.br.

${ }^{7}$ Mestranda em Educação Básica Universidade do Alto Vale do Rio do Peixe - UNIARP. ORCID: 00000002-17836707. E-mail: vanetumelero@hotmail.com.
} 
the study has a qualitative approach, as for the objectives it is exploratory and of bibliographic procedure. The proposed PCE consists of the construction of a robot using recyclable material to re (signify) concepts that have already been studied and to correlate them with other contents such as mathematics, science and arts.

Keywords: Ecoforming Creative Project. Educational Robotics. Recycling.

\section{INTRODUÇÃO}

A necessidade de avaliar as transformações culturais e sociais é cada vez mais necessária. Para Papert (1994), muitas pessoas, atualmente, estão em empregos que nem existiam quando nasceram. As habilidades humanas são aprimoradas em função do contexto histórico e social, sendo primordial aperfeiçoá-las em razão dos recursos existentes. Nesse contexto, o homem aprimora as técnicas visando "[...] a capacidade de aprender novas habilidades, assimilar novos conceitos, avaliar novas situações, lidar com o inesperado. Isso será cada vez mais verdadeiro no futuro: a habilidade para competir tomou-se a habilidade de aprender" (PAPERT, 1994 p. 13).

A robótica computacional pode ser uma ferramenta relevante para desenvolver novas habilidades na educação. Essa ferramante permite instigar constantemente o estudante "[...] a observar, abstrair e inventar, criando seus modelos a partir de materiais diversos do seu cotidiano tais como peças de brinquedos e eletrodomésticos danificados, peças de lego, circuitos eletrônicos [...]." (MAISONNETTE, 2002, p.1).

Em 19 de março de 2020, o curso de robótica do Serviço Social da Indústria de Santa Catarina (SESI-SC) fez a interrompção das aulas presenciais devido ao decreto $n^{\circ} 509$ de 17/03/2020 que suspendeu todas as aulas em Santa Catarina em função da pandemia de COVID-19.

Apesar do Ministério da Educação (MEC) ter autorizado a ocorrência das aulas de forma remota, tal modalidade não foi adotada pelo SESI-SC (em Videira), devido à incompatibilidade entre um dos objetivos, os materiais disponíveis para o curso (ambos voltados para estimular o trabalho em equipe entre os estudantes em atividades práticas) e as medidas de prevenção contra o Covid-19, as quais foram orientadas para o isolamento social.

Dessa maneira, tornou-se necessário adequar a estrutura das aulas de forma que o estudante possa realizar as atividades em casa, preferencialmente, com 
materiais que disponíveis na própria residência (como era a robótica descrita por Maisonnette (2002)) e, ainda, estimulando a participação da família.

Este trabalho propõe um Projeto Criativo Ecoformador (PCE) que permite trabalhar a robótica educacional de forma remota, na perspectiva transdisciplinar e com a participação da família. Apesar do contexto, buscou-se criar um PCE que não fosse específico para a pandemia ou para uma instituição, mas que também possa ser realizado na condição de isolamento social. Para isso, foi realizada uma revisão dos pressupostos epistemológico do PCE, os quais são: o pensamento complexo, a transdisciplinaridade e a ecoformação; bem como a apropriação do conceito de robótica educacional.

\section{FUNDAMENTAÇÃO DO PROJETO CRIATIVO NO CONTEXTO DA ROBÓTICA}

\section{EDUCACIONAL}

A proposta do Projeto Criativo Ecoformador (PCE) é uma estratégia fundamentada na perspectiva do pensamento complexo, transdisciplinar e ecoformadora desenvolvido pelos autores Torre e Zwierewicz (2009).

Os autores afirmam que "[...] um Projeto Criativo Ecoformador representa um referencial de ensino e aprendizagem baseado na autonomia, na transformação, na colaboração e na busca do desenvolvimento integral" (TORRE; ZWIEREWICZ, 2009, p. 155). Além disso, Torre $(2005$, p. 40$)$ descreve que "[...] se quisermos que a criatividade faça parte da educação, temos que antes formar os professores nela, atendendo às três dimensões de conhecimento, habilidades e atitudes."

Para mais, pode-se considerar que "a atitude criativa abre novos horizontes e planos de realidade, movendo-se com facilidade na complexidade e na compreensão. É a atitude para aceitar, inclusive, o que não se compreende e ampliar o valor conhecido" (TORRE, 2009, p. 116). Nessa perspectiva, devemos assumir o compromisso com a mudança escolar e com o desenvolvimento criativo, em que ambos, docentes e discentes, terão papeis fundamentais nos processos de ensino e aprendizagem.

De modo geral, os projetos têm por finalidade incentivar a capacidade de criação, a idealização de conhecimentos novos, a parceria e a interação entre os envolvidos e entre a comunidade. Além disso, os projetos procuram resoluções para os problemas identificados como mobilizadores no processo de adquirir 
conhecimento. Os PCEs também funcionam nesse mesmo entendimento, indo além. De acordo com Zwierewicz (2014), a proposta do PCE está em sua competência e habilidade em ensinar a partir da própria vida, voltando-se a ela com explicações idealizadas e organizadas na sala de aula, por intermédio de meios e circunstâncias que vão mais adiante do conhecimento científico.

\section{TRANSDISCIPLINARIDADE COMO PRINCÍPIO EPISTEMOLÓGICO NECESSÁRIO À CONSTRUÇÃO DO PCE PROPOSTO}

Os processos de ensino e aprendizagem que se articulam com as mais variadas disciplinas e campos de conhecimento demandam uma abordagem transdisciplinar. "A transdisciplinaridade não procura o domínio de várias disciplinas, mas a abertura de todas as disciplinas ao que as une e as ultrapassa" (CETRANS, 1994, p.168). E, "[...] toda e qualquer tentativa de reduzir o ser humano a uma definição e de dissolvê-lo em estruturas formais, sejam quais forem, é incompatível com a visão transdisciplinar" (CETRANS, 1999, p.168).

Outrossim, "[...] a transdisciplinaridade é complementar à abordagem disciplinar; ela faz emergir do confronto das disciplinas novos dados que as articulam entre si, e ela nos oferece uma visão da Natureza e da Realidade" (NICOLESCU, 1999, Art. 3). Nesse viés, a abordagem é feita diante das indagações que interligam e atravessam todas as disciplinas, o que individualmente não é possível responder, unindo, assim, em uma mesma busca, motivada por novas descobertas e pesquisas. Logo, a transdisciplinaridade, que se dá num processo contínuo e com saberes singulares, assim como o sujeito, acontece de forma subjetiva e coletiva, rompendo os modos fragmentados de conhecimento, de agir e de pensar.

Nicolescu (1999, p.50) vê "a transdisciplinaridade, como o prefixo 'trans' indica, diz respeito àquilo que está ao mesmo tempo entre as disciplinas, através das diferentes disciplinas e além de qualquer disciplina". Ademais, de acordo com Suanno (2014, p.121), a transdisciplinaridade está relacionada com "[...] saberes e conhecimentos, que visam estabelecer o diálogo entre filosofia, ciências, culturas e literatura a fim de potencializar a capacidade humana de perceber, compreender e transformar a realidade."

Para se aproximar e compreender as condições humanas utilizando a transdisciplinaridade realizou-se uma busca no catálogo de Teses e Dissertações 
(CTS) da CAPES com uso dos seguintes descritores "sustentabilidade" AND "transdisciplinaridade" AND "educação". Foram encontrados 23 trabalhos, sendo que dois deles foram excluídos por não possuírem relação com o PCE proposto ou pelo fato de o material não estar disponível para acessar o conteúdo completo da dissertação.

O estudo apresentado por Freire (2015) verificou a possibilidade da integração entre ciências e os saberes tradicionais. $O$ autor evidenciou que os saberes acadêmicos e tradicionais possuem o mesmo grau de relevância para os sujeitos envolvidos, mesmo que socialmente o conhecimento científico seja mais valorizado. A transdisciplinaridade se manifesta nas relações mais profundas desenvolvidas entre as áreas e dimensões transversais que aspiram a unidade do conhecimento, demandada como racionalidade do pensamento complexo (FREIRE, 2015. p. 27)

Na pesquisa apresentada por Santos (2008) trás reflexões sobre a inclusão do conteúdo de educação ambiental nos planejamentos escolares. O estudo identificou como resultado que as escolas municipais de Aracaju ainda exploram pouco a aprendizagem por meio da interdisciplinaridade ou da transdisciplinaridade. Assim, apesar da vontade dos professores, os conteúdos são trabalhados de forma descontextualizada entre as disciplinas e com relação ao ambiente local.

Para Santos (2008, p. 61) os "[...] comportamentos mínimos são necessários para o estabelecimento do diálogo a partir do respeito e diferenças entre os mundos dos professores e dos estudantes [...]", possibilitando trabalhar na perspectiva da inter e da transdisnaridade.

Apesar do escopo restrito, dentre os estudos observados (FREIRE, 2015; SANTOS, 2008), foi possível identificar as necessidades e dificuldades de desenvolver métodos para estabelecer propostas pedagógicas criativas.

Por meio das pesquisas apresentadas, observa-se que a abordagem da transdisciplinaridade pode levar o estudante a compreender a integração das áreas do conhecimento e utilizá-la para solucionar problemas do dia a dia, indo além dessa integração, buscando uma proposta de formação que estabelece uma relação de interdependência e respeito com o meio, com o outro e consigo mesmo.

\section{ECOFORMAÇÃO COMO PRINCÍPIO EPISTEMOLÓGICO NECESSÁRIO À}




\section{CONSTRUÇÃO DO PCE PROPOSTO}

Suanno (2014) enfatiza as possibilidades de refletirmos e repensarmos em modelos para o desenvolvimento consciente e cidadão dos estudantes, o que pode ser realizado nos ambientes escolares. Todavia, para que isso possa acontecer há, certamente, uma grande necessidade de uma educação responsável para a vida, um cidadão mais participante e que atue de forma eficiente, com ações e posicionamentos de respeito ao planeta, por se sentir parte desse meio e ao meio ambiente, uma construção com entendimento ecoformador, um intelecto mais prático, tendo em conta as afeições nas suas ações ecossistêmicas.

Nesse âmbito, de acordo com os autores Torre, Moraes e Pujol (2008), a Ecoformação pode ser delineada como um ecossistema composto e sustentado com a intenção de atender o funcionamento de ações educacionais, principalmente em relações com os estudantes, a sociedade e a natureza de modo integral. Isso porque é uma forma de procurar o desenvolvimento e o progresso interno a partir da incorporação de diferentes sentidos, como todo o funcionamento humano e, assim, com a natureza, de forma a ter sua valorização e harmonia.

Ademais, para Gonzáles Velasco (2017) a ecoformação não é apenas algo que pode ser ensinado ou ser aprendido de um modo estanque, mas sim presenciado de uma forma coletiva, constituindo-se, substancialmente, em uma ação de espírito. Essa ação é realizada a partir da curiosidade, sentido aventureiro e sentimentos sobre as conexões existentes entre as coisas, condições que, muitas vezes, passam sem uma observância comum, a fim de ir além, na sensibilidade em relação a si, ao outro e ao próprio ambiente. Essas ações podem ser edificadas e entendidas nas junções dos mais diversos saberes.

A ecoformação, neste processo, dá a educação uma prioridade fundamentada a partir da vida e para a vida, propiciando mudanças que estão implicadas em todo o desenvolvimento do ensino e de aprendizagem, no espaço da sala de aula, no enquadramento das instituições de ensino e nos seus espaços ao redor (TORRE; ZWIEREWICZ, 2009). Nesta significação e discernimento, há um reconhecimento: a capacidade de criação séria e consciente, tendo um equilíbrio interior no que diz respeito às pessoas e ao meio ambiente.

\section{PENSAMENTO COMPLEXO COMO PRINCÍPIO EPISTEMOLÓGICO}




\section{NECESSÁRIO À CONSTRUÇÃO DO PCE PROPOSTO}

O pensamento complexo de Morin nos ajuda a traçar parâmetros para a solução da questão de separação das áreas do conhecimento, da segregação e negação entre subjetivo e objeto, que deveriam andar de mãos dadas (ANTUNES, 2012. p. 9).

De acordo com Morin (2000), é preciso aprender a enfrentar a incerteza, já que vivemos em uma época de mudanças, na qual os valores são ambivalentes e em que tudo é ligado. Assim, é por isso que a educação do futuro deve se voltar para as incertezas ligadas ao conhecimento. Em um primeiro momento, devemos nos remeter ao esclarecimento de como é conceituado o termo "complexo":

[...]. Em consulta ao dicionário Aurélio Buarque de Holanda, encontram-se definições tais quais: de difícil compreensão; complicado; desprovido de percepção, entendimento ou clareza; confuso; que expressa timidez, culpa; sentimento de inferioridade etc. Dentre estes, constam duas expressões, que não estão de acordo com o senso comum, pelo fato de serem coerentes à teoria da complexidade. Primeira: Que abarca e compreende vários elementos ou aspectos distintos cujas múltiplas têm relações de interdependência. Segunda: Construção com inúmeras partes que estão ligadas entre si, formando um todo. A palavra é de origem latina complexus que quer dizer "o que foi tecido junto, o que rodeia, o que inclui". (ABREU, 2017, p.31)

Nesse víes, com o olhar voltado ao contexto educacional, é preciso buscar uma educação que transcenda, que vá além de questões burocráticas de currículo e diretrizes, considerando as ações individuais relacionadas intrinsecamente entre si, de maneira antagônica e complementar.

Para Morin (2003), a educação deve contribuir para a autoformação do indivíduo (ensinar a assumir a condição humana, ensinar a viver) e ensinar como se tornar cidadão. Um cidadão é definido, em uma democracia, por sua solidariedade e responsabilidade. Deve-se tomar consciência, autonomia e tomada de decisão a partir de seu contexto, relacionando-o à sua autoformação, à interação com o outro e, consequentemente, com o meio que está inserido.

O pensamento complexo adquire importância por reagrupar os saberes na
busca da compreensão dos problemas dos seres humanos. É um
pensamento incompleto, inacabado e parcial de todo conhecimento, que
distingue, mas não separa, abraça a diversidade (entrelaçamento) e reúne o
que está separado, considera o contexto e aborda as várias relações
existentes (multidimensional). (ARONE, 2014, p.29)

Diante disso, a escola pode ser considerada como esse espaço complexo, permeada por ações integradas, tecidas juntas, num grande conjunto, da qual 
participa e colabora na formação do sujeito no desenvolvimento de suas particularidades e potencialidades, favorecendo suas dimensões social, cultural, afetiva, econômica, na busca da garantia de um ensino transdisciplinar. Segundo Morin (2003), "uma tal formação deve permitir enraizar, dentro de si, a identidade nacional, a identidade continental e a identidade planetária".

\section{ROBÓTICA EDUCACIONAL COMO PRINCÍPIO EPISTEMOLÓGICO NECESSÁRIO À CONSTRUÇÃO DO PCE PROPOSTO}

Para superar os desafios que a escola enfrenta quanto à formação das novas gerações, propõe-se que a mesma "[...] eduque para usos mais democráticos das tecnologias e para uma participação mais consciente na cultura digital" (BRASIL, 2017, p. 61). Neste sentido, Zilli (2004) defende que a educação visa à promoção do ser humano e muda de acordo com o contexto em que está inserida, ou seja, a educação varia de acordo com o momento histórico. Zilli (2004) destaca, ainda, a busca por facilitar a aquisição de conhecimento como forma de atender as necessidades do mundo atual.

Uma das abordagens que utiliza as tecnologias na educação é a robótica educacional. Essa abordagem, "utiliza os fundamentos e recursos tecnológicos da robótica, através de kits didáticos [...], para a resolução de problemas em diferentes áreas como Matemática, Ciências, Informática, etc” (SANTOS, 2016, p.29).

A robótica educacional não consiste apenas em utilizar robôs em sala de aula, visto que essa abordagem consiste de "[...] uma proposta educacional, apoiada na experimentação e na errância" (ZILLI, 2004, p. 39). A autora defende a possibilidade de uso dessa proposta para demonstrar conceitos teóricos de forma prática, a multidisciplinaridade da robótica e a capacidade de motivar o estudante "[...] que a todo momento é desafiado a observar, abstrair e inventar" (ZILLI, 2004, p. 39).

O autor Bezerra Junior (2018) salienta que a robótica educacional se mostrou como uma metodologia atraente na educação por meio do lúdico que incentiva e desperta aprendizagem, isto é, consiste no desenvolvimento do ensino em que a aprendizagem ocorre na montagem e programação dos robôs, prática que estimula o aprimoramento do conhecimento cognitivo dos estudantes. Mas com a robótica educacional, é possível estabelecer o conhecimento por intermédio das relações sociais, das trocas de conhecimentos e saberes culturais de cada integrante da equipe 
de trabalho.

Nesse sentido, a robótica tem um papel importante no âmbito da educação ao motivar o ensino e a aprendizagem diante de uma nova maneira de se aprender e se desenvolver integralmente, saindo das abordagens tradicionais e construindo novas estratégias. Fica para trás as "cadeiras em fila" e o professor como o centro do processo de ensino, o qual passa a democratizar esse ensino, pois essa abordagem na educação trabalha em pares, equipes que se auxiliam, direcionadas na busca de resolução de problemas de forma colaborativa.

\begin{abstract}
O desenvolvimento das aulas se dá por meio de atividades que envolvem conhecimento científico, integração de técnicas e algoritmos para a criação e programação de robôs. Vinculada a outras estratégias pedagógicas para inclusão de tecnologias no âmbito educacional, o recurso oferece a professores e estudantes, experiências similares as que terão na vida real, a partir de problematizações, requerendo dos alunos ação intensa em sua resolução (ANDRADE, 2018, p. 38)
\end{abstract}

Tendo em vista o quanto são crescentes as tecnologias e que os nativos digitais fazem uso das mesmas nas suas redes de relações pessoais, familiares e de colaboração, há que se considerar o seu uso no contexto escolar. Desta forma, valorizam-se os conhecimentos que os estudantes já possuem e aprimoram no 'círculo da cultura'. Ademais, as tecnologias são atrativas e podem promover o encantamento dos estudantes pela educação. E quando há encantamento, há grandes possibilidades da apredendizagem ocorrer. Assim,

[...] conjectura-se que a aprendizagem se dá de modo extracurricular, em alguns casos de forma interdisciplinar, exigindo do estudante uma aprendizagem individualizada e autodidata. Com vistas para aquisição de ofícios futuros, em decorrência das diferentes áreas de conhecimento abordadas (ANDRADE, 2018, p. 19)

Em consonância a proposta do PCE a ser construído, percebemos a importância em preparar um cidadão para o mundo, consciente em relação ao desperdício e reaproveitamento dos resíduos sólidos, garantindo a reutilização do que futuramente viria a ser lixo, unindo: educação e sustentabilidade, com uma produção de baixo custo, a qual permita desenvolver o senso ambiental e ecológico que pensa e cria um meio social local melhor. A Robótica Educacional é mais um dos benefícios que a tecnologia tem ofertado a essa demanda do século XXI.

\title{
METODOLOGIA
}

A metodologia é de abordagem qualitativa, cujo tipo de pesquisa, quanto aos 
objetivos, se caracteriza como pesquisa exploratória. O procedimento técnico é de pesquisa bibliográfica.

A abordagem qualitativa, amparada por Minayo (2003, p. 22), "[...] aprofundase no mundo dos significados das ações e relações humanas, um lado não perceptível e não captável em equações, médias e estatísticas". Quanto a pesquisa exploratória, essa consiste no aprofundamento do objeto de pesquisa (GIL, 2008). Para Gil, nesse caso, a pesquisa assume uma técnica de dados bibliográfica, pois procura compreender mais sobre o tema, que, nesse contexto, assume o papel de propor um projeto ecoformador aplicando a robótica educacional a partir de recursos recicláveis que os estudantes possuem em casa.

Com a pesquisa bibliográfica é possível investigar os fenômenos explorados (GIL, 2002), o que nos permitiu uma análise e um levantamento de dados a respeito do tema. "A pesquisa bibliográfica não é mera repetição do que já foi dito ou escrito sobre certo assunto, mas propicia o exame de um tema sob novo enfoque ou abordagem, chegando a conclusões inovadoras" (MARCONI e LAKATOS, 2003, p. 183).

Inicialmete foi realizada uma busca para a obtenção de materiais sobre projetos ecoformadores. Na sequência foi feita uma análise na Base Nacional Comum Curricular (BNCC) para estabelecer a interligação e colaboração das diferentes áreas do conhecimento relacionadas ao projeto proposto. E por último, foi necessário um levantamento de algumas produções científicas sobre o tema em estudo.

A proposta tem a intenção de estimular, a partir do projeto proposto, o modo com que os estudantes vivenciam as questões já estudadas em sala de aula e, dessa forma, propiciar o desenvolvimento de um protótipo a partir do lixo reciclável.

\section{RESULTADOS E ANÁLISE}

Com base nos conceitos de transdisciplinaridade, ecoformação, complexidade e robótica educacional, criou-se o PCE: - "o lixo de casa reciclado na robótica". Esse projeto propôs um conjunto de atividades no contexto da construção de um robô de brinquedo, construído com materiais que seriam descartados, principalmente resíduos sólidos recicláveis.

A metodologia do PCE forma-se a partir de uma estrutura composta por dez organizadores conceituais (epítome, legitimação teórica, legitimação pragmática, 
perguntas geradoras, metas, eixos norteadores, itinerários, coordenadas temporais, avaliação emergente e polinização) ancorados em um pensamento organizador objetivam mobilizar docentes e estudantes a transitarem entre conteúdos curriculares e a realidade local e global (TORRE; ZWIEREWICZ, 2009). Os organizadores conceituais do PCE elaborados neste trabalho $s$

Para a Epítome foi construído um vídeo disponibilizado aos estudantes. $O$ vídeo contém alguns materiais reciclados e formas de separá-los. O conteúdo do vídeo apresenta algumas ideias de como os materiais recicláveis podem ser utilizados na construção do robô, de forma a estimular a curiosidade do estudante.

Quanto a Legitimação Teórica, fundamentou-se na transdisciplinaridade, no pensamento complexo e na ecoformação, além do construcionismo de Papert (1994) para corroborar com a ideia de que o estudante constrói o próprio conhecimento a partir da apropriação dos materiais, modelos e metáforas sugeridos pela cultura em que o mesmo está inserido.

$\mathrm{Na}$ Legitimação Pragmática, buscou-se resgatar os conceitos que os estudantes já construíram, por meio de um vídeo. Além disso, foram sugeridos modelos de robôs e fontes de pesquisa para eles utilizarem como fonte de inspiração.

Ademais, quanto às metas do projeto, elas simulam as etapas de um projeto industrial. Para isso, os estudantes podem coletar materiais recicláveis; fazer um esboço do robô a ser construído; construir um protótipo de robô com materiais recicláveis; utilizar uma peça, ou mais, de plástico no robô; utilizar uma peça, ou mais, metálica no robô; utilizar papel ou papelão no robô; permitir que o robô realize ao menos um movimento; colocar um motor para que o robô se movimente sozinho; e produzir um vídeo relatando como foi o projeto. Ao propor essa sequência de atividades, as metas serão apresentadas, evidenciando a possibilidade de adaptá-las ao contexto de cada estudante, visto que nem todos possuem, em casa, um motor prestes a ser descartado e compatível com um robô de brinquedo.

Como eixo norteador geral, almejou-se utilizar a robótica durante o período da quarentena para exercitar a curiosidade intelectual e recorrer à abordagem própria das ciências e da matemática, incluindo a investigação, a reflexão, a análise crítica, a imaginação e a criatividade para investigar causas, elaborar e testar hipóteses, formular e resolver problemas e criar soluções (inclusive tecnológicas) com base nos conhecimentos das diferentes áreas.

Assim, com relação aos objetivos específicos buscou-se estimular a 
criatividade; correlacionar com o conteúdo já repassado; visualizar oportunidades a partir de materiais de casa; entender a importância da reutilização; desenvolver o protagonismo e o exercício da cidadania; estabelecer um contato com as ciências (química, física e biologia), por meio dos materiais recicláveis e suas origens; refletir sobre o impacto que os materiais recicláveis causam ao serem descartados na natureza; experimentar o desenvolvimento de protótipos e estimular a participação da família durante o desenvolvimento do projeto.

Quanto aos recursos, esses dependem do que os estudantes têm disponível em casa. Contudo, foram sugeridas como opções latinhas, caixa de papelão, caixa de leite, garrafas de plástico, clips, brinquedos quebrados, botão de roupa, tampinha, frasco de desodorante vazio, CD/DVD, canudinho, palito de picolé, fita adesiva, cola e barbante.

O projeto foi proposto para ocorrer de setembro de 2020 a março de 2021. As atividades estão organizadas de acordo com apresentado no Quadro 1.

Quadro 1 - Itinerário dos PCE "O lixo de casa reciclado na robótica”

\begin{tabular}{|l|l|}
\hline ATIVIDADES & DESCRIÇÃo \\
\hline Vídeo Inicial & $\begin{array}{l}\text { Apresentação dos materiais, origem, relações com a natureza, dicas, ideias } \\
\text { iniciais e mensagem para começar a coleta. }\end{array}$ \\
\hline $\begin{array}{l}\text { Coleta dos } \\
\text { materiais }\end{array}$ & Classificar os recursos encontrados em casa. \\
\hline $\begin{array}{l}\text { Conversa sobre } \\
\text { o projeto }\end{array}$ & $\begin{array}{l}\text { Apresentação de algumas fotos e vídeos de robôs produzidos com os materiais } \\
\text { recicláveis de referência. }\end{array}$ \\
\hline $\begin{array}{l}\text { Apresentação do } \\
\text { esboço }\end{array}$ & $\begin{array}{l}\text { Apresentação dos materiais necessários para fazer o robô, comparar com os } \\
\text { materiais disponiveise trocar ideias sobre como realizar a montagem. }\end{array}$ \\
\hline $\begin{array}{l}\text { Fabricação do } \\
\text { protótipo }\end{array}$ & $\begin{array}{l}\text { Produção do robô com a ajuda dos familiares, ficando o professor disponível } \\
\text { para troca de ideias em qualquer eventualidade. }\end{array}$ \\
\hline Testes & $\begin{array}{l}\text { Os estudantes serão desafiados a identificar os pontos fortes e fracos do robô, } \\
\text { se ele ficou resistente, se o robô consegue fazer os movimentos desejados, o } \\
\text { que achou da aparência do robô, se é possível brincar com o robô. }\end{array}$ \\
\hline $\begin{array}{l}\text { Gravação dos } \\
\text { Vídeos }\end{array}$ & $\begin{array}{l}\text { Expressarem suas opiniões sobre o projeto, suas dificuldades, o que } \\
\text { aprenderam, mostrar como ficou o robô, contar que materiais usaram, contar o } \\
\text { que gostariam de mudar no robô e o que não mudariam. }\end{array}$ \\
\hline Documentário & Após aprovação será desenvolvido um documentário final. \\
\hline
\end{tabular}

Fonte: Os autores. 
Diante disso, pretende-se avaliar cada estudante a partir da sua própria realidade e ao longo do processo, de acordo com a capacidade demonstrada por intrmédo das atividades propostas na produção do robô. A avaliação emergente também servirá para refletir sobre o próprio projeto, suas falhas e acertos, assim como seu potencial futuro.

Os estudantes serão estimulados a gravar um vídeo mostrando o robô construído, contando sobre o processo de criação (das superações, das escolhas dos materiais) e da experiência a partir do projeto. Os vídeos, uma vez autorizados pelos estudantes e familiares, podem ser compartilhados para promover a Polinização do PCE. O compartilhamento pode ocorrer entre os estudantes envolvidos na construção dos robôs e com as futuras turmas.

Ao concluir o PCE, pretende-se levantar questionamentos para um novo projeto, iniciando-se, assim, um novo ciclo. Com isso, essa proposta pretende estimular a busca contínua dos estudantes por novos conhecimentos, simultaneamente instigando a criatividade, atitudes sustentáveis de participação e cooperação com o próximo.

\section{CONSIDERAÇÕES FINAIS}

As tecnologias vêm ampliando novas e grandes possibilidades na educação, sendo que a robótica educacional é uma delas, tendo em vista que é incentivadora da aprendizagem de uma maneira lúdica. Contudo, a utilização da robótica costuma estar associada a custos elevados por conta dos materiais utilizados no desenvolvimento dos robôs, o que difere da proposta deste estudo. A robótica educacional traz muitas possibilidades de aprender e ensinar; de ser, viver e se relacionar consigo, com o outro e o meio. Essa dinamização se efetiva quando a robótica perpassa e se alicerça nos conceitos da transdisciplinaridade, a ecoformação e o pensamento complexo.

Diante desta percepção com a robótica, é possível implementar novas visões para que os estudantes possam, assim, perceber o meio em que estão inseridos e oportunizar um novo olhar, um olhar mais crítico e consciente quanto ao reuso e descarte correto dos materiais resicláveis.

A partir do exposto, o referido artigo apresentou uma proposta de um PCE que permite trabalhar a robótica educacional de forma remota e com o estímulo da familiar. 
O projeto proposto tenta resgatar conceitos que já foram estudados para correlação de conteúdos com outras áreas do conhecimento, tais como a matemática, a ciência e a arte, além de incentivar o protagonismo e a aproximação familiar.

Para a efetivação a proposta, o estudante precisa coletar diversos materiais disponíveis em casa necessários para a prototipação do robô. É possível considerar que esse processo articula conhecimetnos de diversas áreas do conhecimento, incentivando a curiosidade intelectual, movimentos e criatividade.

Como recomendações de trabalho futuro, sugere-se a implementação do PCE não apenas para o curso de robótica do SESI, mas também para qualquer curso que pretenda trabalhar a reciclagem de maneira transdisciplinar, ecoformadora e que estimule o pensar complexo.

\section{REFERÊNCIAS}

ABREU, Joel Santos de. A Afetividade em Edgar Morin e Sigmund Freud: Um Olhar para a Educação. 2017. 104 f. Dissertação (Mestrado em Educação) Universidade Nove de Julho. São Paulo.

ANDRADE, Fabiana de Oliveira. Robótica Educacional: um estudo da aprendizagem no Colégio Estadual Secretário Francisco Rosa Santos (2013-2016). 2018. 114 f. Dissertação (Mestrado em Educação) - Universidade Tiradentes. Aracaju.

ANTUNES, Janaína Quintas. O Diálogo e a Reflexão nas Artes, Educação e Filosofia Contemporâneas, e sua Relação com as Teorias de Paulo Freire e Edgar Morin. Revista Saber Acadêmico. 13 jun. 2012.

ARONE, Mariangelica. Autoformação Docente à Luz do Pensamento Complexo. 2014. 266 f. Tese (doutorado) - Universidade Nove de Julho. São Paulo.

BEZERRA JUNIOR, José Etiene. Investigando o Uso do Extreme Programming Como uma Metodologia de Ensino para Aplicações Práticas da Robótica Educacional. 2018. 124 f. Dissertação (Mestrado em Programa de PósGraduação em Ciência da Computação) - Universidade do Estado do Rio Grande do Norte. Mossoró.

BRASIL, Base Nacional Comum Curricular: Educação é a base. Brasília. 2017. Disponível em:

http://basenacionalcomum.mec.gov.br/images/BNCC_EI_EF_110518_versaofinal_sit e.pdf Acesso em: 14 ago. 2020.

CETRANS - Centro de Educação Transdisciplinar. Educação e Transdisciplinaridade. São Paulo, 1999. Disponível em: http://unesdoc.unesco.org/images/0012/001275/127511por.pdf . Acesso em: 20 de Setembro de 2020. 
FREIRE, Ludmila de Almeida. A Universidade e a Questão do Conhecimento - 0 Currículo Acadêmico na Perspectiva da Inter/Transdisciplinaridade e da Ecologia de Saberes. 2015. 116 f. Tese (Doutorado em Educação Brasileira) Universidade Federal Do Ceará. Fortaleza. Disponível em:

https://repositorio.ufrn.br/jspui/bitstream/123456789/18853/1/MariaAuxiliadoraFS.pdf

GIL, Antonio Carlos. Como elaborar projetos de pesquisa. 4. ed. São Paulo: Atlas, 2002.

GIL, Antonio Carlos. Métodos e técnicas de pesquisa social. 6 ed. São Paulo: Atlas, 2008.

GONZÁLES VELASCO, Juan Miguel. Religaje educativo: espacio-tiempo. La Paz: Prisa, 2017.

MAISONNETTE, Roger. A utilização dos recursos informatizados a partir de uma relação inventiva com a máquina: a robótica educativa. In: Proinfo Programa Nacional de Informática na Educação - Paraná. Disponível em: http://livrozilla.com/doc/1690955/a-utiliza\%C3\%A7\%C3\%A3o-dos-recursosinformatizados-a-partir-de-uma-.... Acesso em: 26 set. 2020

MARCONI, M. A.; LAKATOS, E. M. Fundamentos da Metodologia Científica- 5 Ed. São Paulo - SP: Editora Atlas, 2003.

MINAYO, Marília Cecília de Souza (Org.). Pesquisa Social: teoria, método e criatividade. 21 ed. Petrópolis, RJ: Vozes, 2002.

MORIN, Edgar. Os sete saberes necessários à educação do futuro. $2^{\mathrm{a}}$ ed. São Paulo: Cortez: Brasília, DF: UNESCO, 2000.

MORIN, Edgar. A cabeça bem-feita: repensar a reforma, reformar o pensamento. 8a ed. Rio de Janeiro: Bertrand Brasil, 2003.

NICOLESCU, Basarab. O Manifesto da transdisciplinaridade. Tradução de Lucia Pereira de Souza. São Paulo: TRIOM, 1999.

PAPERT, Seymour. A Máquina das Crianças: Repensando a Escola na Era da Informática. Porto Alegre: Artes Médicas, 1994.

SANTOS, Maria Auxiliadora Ferreira dos. Análise do Processo de Internalização de Propostas de Educação Ambiental em Escolas de Ensino Médio no Município de Aracajú - CE. 2008. 111 f. Dissertação (Mestrado em Geografia) Universidade Federal do Rio Grande do Norte, Natal.

SANTOS, M.E. Ensino das Relações Métricas do Triângulo Retângulo com Robótica Educacional. 2016 197f. Dissertação (Mestrado Profissional em Ensino Tecnológico) -Instituto Federal de Educação, Ciência e Tecnologia do Amazonas, Manaus.

SUANNO, João Henrique. Ecoformação, transdisciplinaridade e criatividade: a escola e a formação do cidadão do século XXI. In: MORAES, Maria Cândida; SUANNO, João Henrique. O pensar complexo na educação: sustentabilidade, 
transdisciplinaridade e criatividade. Rio de Janeiro: Wak Editora, 2014.

SUANNO, Marilza Vanessa Rosa. Em busca da compreensão do conceito de transdisciplinaridade. In: MORAES, Maria Cândida; SUANNO, João Henrique. O pensar complexo na educação: sustentabilidade, transdisciplinaridade e criatividade. Rio de Janeiro: Wak Editora, 2014.

TORRE, Saturnino de La; MORAES, Maria Cândida; PUJOL, María Antónia.

Transdisciplinaridade e ecoformação: um novo olhar sobre a educação. São Paulo: Triom, 2008.

TORRE, Saturnino de la. Dialogando com a criatividade. Tradução de Cristina Mendes Rodríguez. São Paulo: Madras, 2005.

TORRE, Saturnino e ZWIEREWICZ, Marlene. Projetos criativos ecoformadores. In: TORRE, Saturnino e ZWIEREWICZ, Marlene (coord.). Uma escola para o século XXI: escolas criativas e resiliência na educação. Florianópolis: Insular, 2009.

ZILLI, S. A Robótica Educacional no Ensino Fundamental: Perspectivas e Prática. 2004. 89 f. Dissertação (Mestrado em Educação) - Universidade Federal de Santa Catarina, Florianópolis.

ZWIEREWICZ, M. Projetos Criativos e Ecoformadores - PCE: inovação metodológica e estímulo à transdisciplinaridade no Ensino Superior. In: ZWIEREWICZ, M. (Org.). Criatividade e inovação no ensino superior: experiências latino-americanas e europeias em foco. Blumenau: Nova Letra, 2014. 